\title{
Prior statin use and 90-day mortality in Gram-negative and Gram-positive bloodstream infection: a prospective observational study
}

\author{
A. Mehl • S. Harthug • S. Lydersen • J. Paulsen • B. O. Åsvold • \\ E. Solligård • J. K. Damås • T.-H. Edna
}

Received: 18 July 2014 / Accepted: 20 October 2014 / Published online: 6 November 2014

(C) The Author(s) 2014. This article is published with open access at Springerlink.com

\begin{abstract}
In several studies on patients with bloodstream infection (BSI), prior use of statins has been associated with improved survival. Gram-positive and Gram-negative bacteria alert the innate immune system in different ways. We, therefore, studied whether the relation between prior statin use and 90-day total mortality differed between Gram-positive and
\end{abstract}

A. Mehl $(\bowtie) \cdot$ J. Paulsen

Department of Medicine, Levanger Hospital, Nord-Trøndelag

Hospital Trust, Post Box 333, 7601 Levanger, Norway

e-mail: arne.mehl@hnt.no

J. Paulsen

e-mail: julie.paulsen@ntnu.no

\section{A. Mehl • T.-H. Edna}

Unit for Applied Clinical Research, Department of Cancer Research and Molecular Medicine, Norwegian University of Science and

Technology, Trondheim, Norway

T.-H. Edna

e-mail: tom-harald.edna@ntnu.no

\section{S. Harthug}

Department of Medicine, Haukeland University Hospital, Bergen, Norway

e-mail: stig.harthug@helse-bergen.no

\section{S. Harthug}

Institute of Medicine, University of Bergen, Bergen, Norway

\section{S. Lydersen}

Regional Centre for Child and Youth Mental Health and Child

Welfare - Central Norway, Norwegian University of Science and

Technology, Trondheim, Norway

e-mail: stian.lydersen@ntnu.no

J. Paulsen · J. K. Damås

Centre of Molecular Inflammation Research, Department of Cancer Research and Molecular Medicine, Norwegian University of Science and Technology, Trondheim, Norway

J. K. Damås

e-mail: jan.k.damas@ntnu.no
Gram-negative BSI. We conducted a prospective observational cohort study of 1,408 adults with BSI admitted to Levanger Hospital between January 1, 2002, and December 31, 2011. Data on the use of statins and other medications at admission, comorbidities, functional status, treatment, and outcome were obtained from the patients' hospital records. The relation of

B. O. Åsvold

Department of Public Health, Norwegian University of Science and Technology, Trondheim, Norway

e-mail: bjorn.o.asvold@ntnu.no

\section{B. O. Åsvold}

Department of Endocrinology, St. Olav's Hospital, Trondheim University Hospital, Trondheim, Norway

\section{E. Solligård}

Clinic of Anesthesia and Intensive Care, St. Olav's Hospital, Trondheim University Hospital, Trondheim, Norway e-mail: erik.solligard@ntnu.no

\section{E. Solligård}

Department of Circulation and Medical Imaging, Norwegian University of Science and Technology, Trondheim, Norway

\author{
J. K. Damås \\ Department of Infectious Diseases, St. Olav's Hospital, Trondheim \\ University Hospital, Trondheim, Norway
}

\section{T.-H. Edna}

Department of Surgery, Levanger Hospital, Nord-Trøndelag Hospital Trust, Levanger, Norway 
statin use with 90-day mortality differed between Gramnegative and Gram-positive BSI ( $p$-value for interaction 0.01). Among patients with Gram-negative BSI, statin users had significantly lower 90 -day total mortality [odds ratio (OR) $0.42,95 \%$ confidence interval (CI) $0.23-0.75, p=0.003]$. The association remained essentially unchanged after adjusting for the effect of sex, age, functional status before the infection, and underlying diseases that were considered confounders (adjusted OR 0.38, $95 \%$ CI 0.20-0.72, $p=0.003$ ). A similar analysis of patients with Gram-positive BSI showed no association of statin use with mortality (adjusted OR 1.22, $95 \%$ CI $0.69-2.17, p=0.49$ ). The present study suggests that prior statin use is associated with a lower 90-day total mortality in Gram-negative BSI, but not in Gram-positive BSI.

\section{Background}

In spite of antibiotic and supportive therapy, bloodstream infection (BSI) is still a major cause of mortality and morbidity [1-3]. Measures to improve outcomes from BSI are necessary. Several observational studies have assessed the relation between prior use of statins [3-hydroxy-3-methylglutaryl coenzyme A (HMG CoA) reductase inhibitors] and the outcome of BSI. The majority of the studies suggest that statin use could have a beneficial effect in patients with BSI [4-8], whereas some studies have shown no difference in mortality between statin users and non-users [9-11].

Many former studies assessing the relation between statin use and outcome of infection have not had verified BSI, nor have they discriminated between Gram-positive and Gramnegative etiology. As Gram-positive and Gram-negative bacteria alert the innate immune system in different ways [12, 13], drugs that have anti-inflammatory properties may not have the same effect in Gram-positive infection as they do in Gramnegative infection. Only a few authors have attempted to study this issue in patients $[4,7,10,11]$, and the results diverge. In this prospective observational cohort study on BSI, we chose to investigate the relation between prior statin use and 90-day mortality in Gram-positive and Gram-negative BSI separately.

\section{Materials and methods}

Levanger Hospital serves a population of 87,000 as an emergency facility in a defined geographical area. Since 1994, all positive blood cultures at the hospital have been prospectively recorded for surveillance purposes, and clinical information has been recorded, in the following way: whenever a positive blood culture was reported, a physician at the clinical ward filled out a registration form. A team of three research nurses, a subordinate doctor, and the main investigator reviewed the patients' records to verify the data and record additional variables. Data on statin use were prospectively included in the database from 2005, when we became aware of the early studies on statin use and sepsis. Information on the use of statins during the period 2002-2005 was recorded retrospectively from hospital records. The present study includes BSIs occurring between January 1, 2002 and December 31, 2011 in patients $\geq 16$ years of age. BACTEC 9240 (Becton Dickinson Diagnostic Instrument Systems, Sparks, MD) was used for blood culture testing [14]. If a blood culture was positive for bacteria known to cause sepsis, only one positive vial was required for inclusion in the present study. For common skin contaminants (coagulase-negative staphylococci, alphahemolytic streptococci, corynebacteria, etc.), at least two positive vials from separate venipunctures were required. An episode of BSI was classified as polymicrobial if more than one organism was isolated from one or more blood cultures within a 72-h period.

For patients who had more than one episode with positive blood culture in the 10-year period, only the first episode was selected for this study. This cohort consisted of 1,408 patients. BSI with Gram-negative or Gram-positive bacteremia accounted for 1,356 episodes. The remaining cases consisted of eight candidemias and 44 with mixed polymicrobial infection.

The exposure variable was prior statin use, defined as taking a statin in the week before the time of positive blood culture [15]. Two patients, whose statins were discontinued more than one week before the date of the positive blood culture, were categorized as non-statin users. We recorded statin use and the specific statin and dosage from the patients' hospital charts. The outcome variable was death from all causes within 90 days after the first positive blood culture [16]. The date of death was obtained from the patients' electronic records, which is updated by the Civil Registration System in Norway. The following variables were a priori determined as possible confounders because they might be associated with both statin use and mortality from BSI (Table 1): age ( $<65$ years, $65-79$ years, $\geq 80$ years); sex; comorbidities; Charlson comorbidity index [17], categorized as low (no underlying disease score), medium (score 1-2), or high (score >2) [7]; nursing home resident (yes/no); functional status (independent, partly independent, dependent, unknown); immunosuppressive therapy; alcohol abuse; smoking (no smoking, former smoker, present smoker); focus of infection (urinary tract, lungs, biliary tract, gastrointestinal tract, other, unknown); use of antibiotics before admission; and place of acquisition (community, healthcare, hospital). Whether the current BSI episode was nosocomial, healthcare-associated, or community-acquired was determined according to commonly used definitions $[18,19]$.

Variables expressing the severity of the current BSI (systemic inflammatory response syndrome, organ failure, hypotension, hypoperfusion, sepsis, severe sepsis, and septic shock [20]), severe organ failure (defined as SOFA score $>2$ in any 
Table 1 Baseline characteristics of 1,356 adult patients with Gram-negative or Gram-positive bloodstream infection (BSI) by statin use at Levanger Hospital, Norway, 2002-2011

\begin{tabular}{|c|c|c|c|c|c|c|}
\hline \multirow[t]{2}{*}{ Variable } & \multicolumn{3}{|c|}{ Gram-negative BSI $(n=784)$} & \multicolumn{3}{|c|}{ Gram-positive BSI $(n=572)$} \\
\hline & $\begin{array}{l}\text { No statin use } \\
(n=646)\end{array}$ & $\begin{array}{l}\text { Statin use } \\
(n=138)\end{array}$ & $p$-Value & $\begin{array}{l}\text { No statin use } \\
(n=474)\end{array}$ & $\begin{array}{l}\text { Statin use } \\
(n=98)\end{array}$ & $p$-Value \\
\hline Age & & & $<0.001$ & & & 0.021 \\
\hline$<65$ years & 185 (28.6) & $25(18.1)$ & & $159(33.5)$ & $26(26.5)$ & \\
\hline $65-79$ years & $189(29.3)$ & $71(51.4)$ & & $153(32.3)$ & $45(45.9)$ & \\
\hline$\geq 80$ years & $272(42.1)$ & $42(30.4)$ & & $162(34.2)$ & $27(27.6)$ & \\
\hline Female sex & $367(56.8)$ & $67(48.6)$ & 0.060 & $196(41.4)$ & $35(35.7)$ & 0.29 \\
\hline Chronic renal insufficiency & $52(8.0)$ & $16(11.6)$ & 0.17 & $36(7.6)$ & $19(19.4)$ & $<0.001$ \\
\hline \multicolumn{7}{|l|}{ Malignancy } \\
\hline Solid tumor & $148(22.9)$ & $32(23.2)$ & 0.94 & $99(20.9)$ & $21(21.4)$ & 0.93 \\
\hline Hematological cancer & $35(5.4)$ & $3(2.2)$ & 0.11 & $38(8.0)$ & $3(3.1)$ & 0.085 \\
\hline Diabetes mellitus & $87(13.5)$ & $41(29.7)$ & $<0.001$ & $70(14.8)$ & $35(35.7)$ & $<0.001$ \\
\hline Hypertension & $186(28.8)$ & $77(55.8)$ & $<0.001$ & $127(26.8)$ & $40(40.8)$ & 0.003 \\
\hline Cardiovascular disease & $212(32.8)$ & $91(65.9)$ & $<0.001$ & $153(32.3)$ & $67(68.4)$ & $<0.001$ \\
\hline Coronary heart disease & $118(18.3)$ & $65(47.1)$ & $<0.001$ & $88(18.6)$ & $50(51.0)$ & $<0.001$ \\
\hline Congestive heart failure & $59(9.1)$ & $16(11.6)$ & 0.36 & $49(10.3)$ & $14(14.3)$ & 0.25 \\
\hline Peripheral vascular disease & $35(5.4)$ & $15(10.9)$ & 0.016 & $30(6.3)$ & $18(18.4)$ & $<0.001$ \\
\hline Cerebral vascular disease & 77 (11.9) & $32(23.2)$ & $<0.001$ & $52(11.0)$ & $18(18.4)$ & 0.041 \\
\hline Chronic liver disease & $10(1.5)$ & $1(0.7)$ & 0.54 & $14(3.0)$ & $1(1.0)$ & 0.31 \\
\hline Chronic pulmonary disease & $94(14.6)$ & $24(17.4)$ & 0.41 & $78(16.5)$ & $16(16.3)$ & 0.99 \\
\hline Rheumatological/immunological disease & $55(8.5)$ & $13(9.4)$ & 0.72 & $44(9.3)$ & $11(11.2)$ & 0.56 \\
\hline Charlson comorbidity index & & & 0.014 & & & $<0.001$ \\
\hline Low $(0)$ & $187(28.9)$ & $23(16.7)$ & & $144(30.4)$ & $10(10.2)$ & \\
\hline Medium (1-2) & $278(43.0)$ & $69(50.0)$ & & $209(44.1)$ & $43(43.9)$ & \\
\hline $\operatorname{High}(>2)$ & $181(28.0)$ & $46(33.3)$ & & $121(25.5)$ & $45(45.9)$ & \\
\hline Nursing home resident & $85(13.2)$ & $8(5.8)$ & 0.021 & $47(9.9)$ & $2(2.0)$ & 0.017 \\
\hline Functional status prior to the present BSI & & & $0.050^{*}$ & & & $0.035^{*}$ \\
\hline Independent & $365(56.5)$ & $87(63.0)$ & & $307(64.8)$ & $70(71.4)$ & \\
\hline Partly independent & $178(27.6)$ & $38(27.5)$ & & $108(22.8)$ & $26(26.5)$ & \\
\hline Dependent & $97(15.0)$ & $11(8.0)$ & & $52(11.0)$ & $2(2.1)$ & \\
\hline Unknown & $6(0.9)$ & $2(1.4)$ & & $7(1.5)$ & 0 & \\
\hline Immunosuppressive therapy & $86(13.3)$ & $19(13.8)$ & 0.79 & $62(13.1)$ & $13(13.3)$ & 0.93 \\
\hline Alcohol abuse & $30(4.6)$ & $4(2.9)$ & 0.45 & $20(4.2)$ & $2(2.0)$ & 0.38 \\
\hline \multicolumn{7}{|l|}{ Smoking } \\
\hline Non-smoker & $416(64.4)$ & $74(53.6)$ & 0.017 & $278(58.6)$ & $49(50.0)$ & 0.14 \\
\hline Former smoker & $110(17.0)$ & $38(27.5)$ & 0.004 & $105(22.2)$ & $33(33.7)$ & 0.026 \\
\hline Present smoker & $120(18.6)$ & $26(18.8)$ & 0.92 & $91(19.2)$ & $16(16.3)$ & 0.65 \\
\hline \multicolumn{7}{|l|}{ Focus of infection } \\
\hline Urinary tract & $358(55.4)$ & $76(55.1)$ & 0.98 & $45(9.5)$ & $10(10.2)$ & 0.83 \\
\hline Lungs & $46(7.1)$ & $5(3.6)$ & 0.15 & $164(34.6)$ & $31(31.6)$ & 0.67 \\
\hline Biliary tract & $95(14.7)$ & $26(18.8)$ & 0.21 & $14(3.0)$ & $5(5.1)$ & 0.32 \\
\hline Gastrointestinal tract & $49(7.6)$ & $8(5.8)$ & 0.38 & $11(2.3)$ & $2(2.0)$ & 0.81 \\
\hline Skin or soft tissue & $17(2.6)$ & $2(1.4)$ & 0.45 & $66(13.9)$ & $13(13.3)$ & 0.71 \\
\hline Other & $25(3.9)$ & $4(2.9)$ & 0.69 & $105(22.2)$ & $28(28.6)$ & 0.16 \\
\hline Unknown & $56(8.7)$ & $17(12.3)$ & 0.17 & $69(14.6)$ & $9(9.2)$ & 0.16 \\
\hline Systemic antibiotic therapy before admission & $93(14.4)$ & $20(14.5)$ & 0.99 & $49(10.3)$ & $4(4.1)$ & 0.076 \\
\hline
\end{tabular}


Table 1 (continued)

\begin{tabular}{|c|c|c|c|c|c|c|}
\hline \multirow[t]{2}{*}{ Variable } & \multicolumn{3}{|c|}{ Gram-negative BSI $(n=784)$} & \multicolumn{3}{|c|}{ Gram-positive BSI $(n=572)$} \\
\hline & $\begin{array}{l}\text { No statin use } \\
(n=646)\end{array}$ & $\begin{array}{l}\text { Statin use } \\
(n=138)\end{array}$ & $p$-Value & $\begin{array}{l}\text { No statin use } \\
(n=474)\end{array}$ & $\begin{array}{l}\text { Statin use } \\
(n=98)\end{array}$ & $p$-Value \\
\hline \multicolumn{7}{|l|}{ Place of acquisition } \\
\hline Community-acquired & $335(51.9)$ & $76(55.1)$ & 0.52 & $262(55.3)$ & $49(50.0)$ & 0.44 \\
\hline Acquired in hospital & $76(11.8)$ & $21(15.2)$ & 0.28 & $73(15.4)$ & $16(16.3)$ & 0.81 \\
\hline Healthcare-associated & $235(36.4)$ & $41(29.7)$ & 0.15 & $139(29.3)$ & $33(33.7)$ & 0.51 \\
\hline \multicolumn{7}{|l|}{ Variables expressing the severity of infection } \\
\hline Severe sepsis or septic shock at the time of diagnosis & $149(23.1)$ & $25(18.1)$ & 0.22 & $95(20.0)$ & $25(25.5)$ & 0.22 \\
\hline $\begin{array}{l}\text { Severe organ failure (SOFA score }>2 \text { in any organ) at } \\
\text { the time of diagnosis }\end{array}$ & $90(13.9)$ & $19(13.8)$ & $>0.99$ & $75(15.8)$ & $21(21.4)$ & 0.18 \\
\hline Stay in intensive care unit (ICU) & $117(18.1)$ & $26(18.8)$ & 0.81 & $107(22.6)$ & $36(36.7)$ & 0.005 \\
\hline Appropriate initial antibiotic therapy & $548(84.8)$ & $122(88.4)$ & 0.35 & $397(83.8)$ & $88(89.8)$ & 0.16 \\
\hline
\end{tabular}

Data are presented as number of patients (\%)

*Excluding unknowns

organ $[15,21])$, and admission to an intensive care unit (ICU) were recorded, but not considered confounders. Instead, they may be mediators in the pathway between prior statin use and mortality and, therefore, should not be adjusted for in the analyses [7, 22, 23].

Appropriate initial antibiotic therapy was defined as correctly dosed intravenous antibiotic therapy given within $24 \mathrm{~h}$ of the time that the blood culture specimen was obtained, with a regimen that was active in vitro against the microbe(s) isolated from blood culture(s) [24]. This variable was not adjusted for in the main analyses, as it was not considered a confounder. Appropriate initial antibiotic therapy is, indeed, strongly associated with outcome of BSI, but it is not associated with prior statin use in such a way that it influences whether a person has been prescribed statin medication. Prior statin use may be associated with the initial antibiotic therapy if statin use mitigates the inflammatory response so that symptoms are masked and, therefore, appropriate initial antibiotic therapy, is delayed. In this case, appropriate initial antibiotic therapy is a mediator in the pathway between statin use and death, and not a confounder. On the other hand, one might postulate some unknown variable that influences whether people are prescribed statin medication and also influences whether they receive appropriate initial antibiotic therapy (e.g., some underlying condition that is not included in the Charlson comorbidity index). To reduce the influence of such an unknown confounder, we also performed an analysis including adjustment for appropriate initial antibiotic therapy.

\section{Ethics}

The Regional Committee for Ethics in Medical Research, Health Region IV, Norway approved the study. The Ethics Committee waived the need for informed consent because this was an observational study, the treatment of the patients was standard, and no samples were taken for the purposes of the research.

\section{Statistical analyses}

Proportions were compared using the unconditional z-pooled test, which is the unconditional version of the Pearson Chisquared test [25]. Unordered $\mathrm{r} \times \mathrm{c}$ tables were analyzed using the exact version of the Pearson Chi-squared test. The exact Cochran-Armitage test was used to test for trends in proportions. Univariable analysis of mortality curves was done with KaplanMeier analysis. The relation between prior statin use and 90-day total mortality was analyzed using logistic regression. Estimates were accompanied by $95 \%$ confidence intervals (CIs). Two-sided $p$-values $<0.05$ were considered significant. Statistical analyses were performed with SPSS 18 and StatXact 9.

\section{Results}

During the 10-year period, 784 patients with Gram-negative BSI and 572 with Gram-positive BSI were identified. 17.6\% of those with Gram-negative and $17.1 \%$ of those with Grampositive BSI were statin users. The patient characteristics are shown in Table 1. In both Gram-negative and Gram-positive BSI, statin users had a higher burden of comorbid diseases, such as diabetes, hypertension, and cardiovascular disease, and they also had a higher Charlson comorbidity index. Variables expressing the severity of infection at the time of diagnosis were not significantly different in statin users and non-users. In Gram-positive BSI, the proportion of patients admitted to an ICU was higher in statin users. 
Table 2 Microbial agents in 784 episodes of Gram-negative BSI and 572 episodes of Gram-positive BSI, total and by statin use

\begin{tabular}{|c|c|c|c|c|}
\hline Microbial agent(s) & No statin & Statin & Total & $p$-Value \\
\hline \multicolumn{5}{|l|}{ Gram-negative microorganisms } \\
\hline Escherichia coli & $400(61.9)$ & $95(68.8)$ & $495(63.1)$ & 0.13 \\
\hline Klebsiella spp. & $54(8.4)$ & $20(14.5)$ & $74(9.4)$ & 0.025 \\
\hline Proteus spp. & $29(4.5)$ & $3(2.2)$ & $32(4.1)$ & 0.21 \\
\hline Enterobacter spp. & $20(3.1)$ & $3(2.2)$ & $23(2.9)$ & 0.69 \\
\hline Other Enterobacteriaceae & $19(2.9)$ & $6(4.3)$ & $25(3.2)$ & 0.44 \\
\hline Pseudomonas spp. & $35(5.4)$ & $5(3.6)$ & $40(5.1)$ & 0.44 \\
\hline Haemophilus influenzae & $15(2.3)$ & 0 & $15(1.9)$ & 0.079 \\
\hline Neisseria meningitidis & $8(1.2)$ & 0 & $8(1.0)$ & 0.20 \\
\hline Other aerobic Gram-negative organisms & $10(1.5)$ & 0 & $10(1.3)$ & 0.14 \\
\hline Anaerobic Gram-negative rods & $28(4.3)$ & $5(3.6)$ & $33(4.2)$ & 0.88 \\
\hline Mixed Gram-negative aerobic or anaerobic rods & $28(4.3)$ & $1(0.7)$ & $29(3.7)$ & 0.079 \\
\hline Total Gram-negative microorganisms & $646(100)$ & $138(100)$ & $784(100)$ & \\
\hline \multicolumn{5}{|l|}{ Gram-positive microorganisms } \\
\hline Streptococcus pneumoniae & $162(34.2)$ & $27(27.6)$ & $189(33.0)$ & 0.23 \\
\hline Staphylococcus aureus & $120(25.3)$ & $32(32.7)$ & $152(26.6)$ & 0.12 \\
\hline Beta-hemolytic streptococci & $70(14.8)$ & $13(13.3)$ & $83(14.5)$ & 0.74 \\
\hline Enterococcus spp. & $42(8.9)$ & $10(10.2)$ & $52(9.1)$ & 0.66 \\
\hline Viridans group streptococci & $33(7.0)$ & $7(7.1)$ & $40(7.0)$ & 0.94 \\
\hline Coagulase-negative staphylococci & $33(7.0)$ & $6(6.1)$ & $39(6.8)$ & 0.88 \\
\hline Listeria monocytogenes & $3(0.6)$ & $1(1.0)$ & $4(0.7)$ & 0.88 \\
\hline Anaerobic Gram-positive microorganisms & $6(1.3)$ & $1(1.0)$ & $7(1.2)$ & 0.89 \\
\hline Mixed Gram-positive aerobic or anaerobic BSI & $5(1.1)$ & $1(1.0)$ & $6(1.0)$ & 0.68 \\
\hline Total Gram-positive microorganisms & $474(100)$ & $98(100)$ & $572(100)$ & \\
\hline
\end{tabular}

Data are presented as number of patients $(\%)$

The distribution of the microbial agents in relation to statin use is shown in Table 2. The distribution of microbes was essentially similar among statin users and non-users, except that Klebsiella spp. were more common among statin users and that some Gram-negative microbes (Haemophilus influenzae, Neisseria meningitidis and "Other aerobic Gramnegative organisms") did not occur in statin users.

Figure 1 shows the mortality curves for patients with Gram-negative and Gram-positive BSI. In Gram-negative BSI, the total 90 -day mortality was $10.1 \%(14 / 138)$ in statin users and $21.4 \%(138 / 645)$ in non-statin users, $p=0.002$. In Gram-positive BSI, the total 90-day mortality was $28.6 \%$ (28/ $98)$ in statin users and $27.0 \%(128 / 474)$ in non-statin users, $p=0.90$.

The results of logistic regression analysis of the relation between statin use and 90-day total mortality are shown in Table 3. For the total BSI cohort, we found a negative association between prior statin use and 90-day mortality [odds ratio (OR) $0.69,95 \% \mathrm{CI} 0.49-0.98, p=0.040$ ). The association was not mitigated by adjustment for possible confounding factors. Among patients with Gram-negative BSI, the mortality was significantly lower in statin users (OR $0.42,95 \% \mathrm{CI}$
0.23-0.75, $p=0.003)$. In Gram-positive BSI, there was no association between statin use and mortality. Adjustment for variables considered confounders did not weaken the association between statin use and 90-day mortality in Gram-

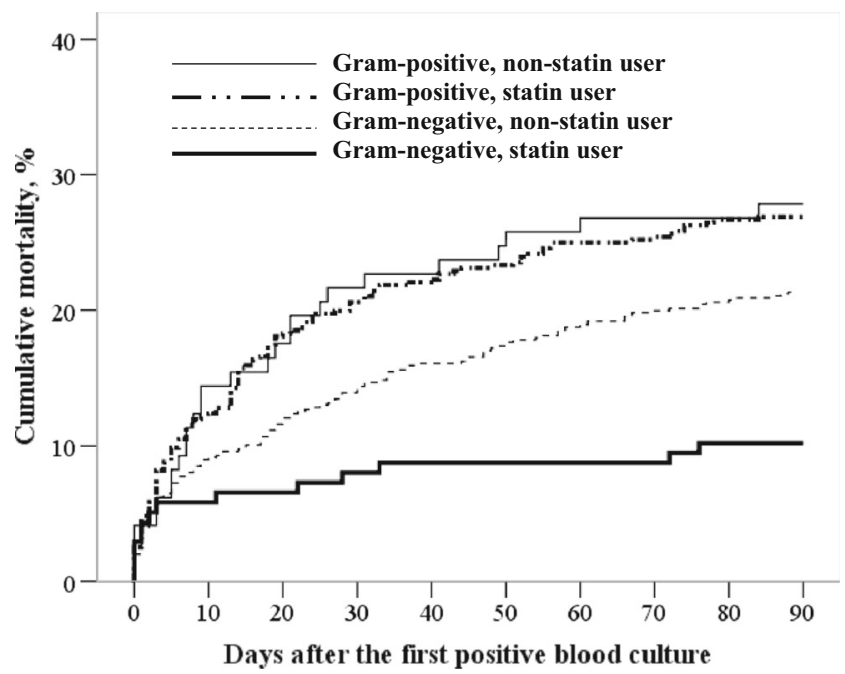

Fig. 1 Mortality curves for patients with Gram-negative and Grampositive bloodstream infection (BSI) stratified by statin use 
Table 3 Logistic regression analysis of the relation between prior statin use and 90-day total mortality

\begin{tabular}{|c|c|c|c|c|c|}
\hline & No. of deaths/patients (\%) & $\begin{array}{l}\text { Unadjusted OR } \\
(95 \% \mathrm{CI})\end{array}$ & $p$-Value & $\begin{array}{l}\text { Adjusted* OR } \\
(95 \% \mathrm{CI})\end{array}$ & $p$-Value \\
\hline \multicolumn{6}{|l|}{ Any BSI } \\
\hline No statin & $285 / 1,164(24.5)$ & 1 (reference) & & 1 (reference) & \\
\hline Statin & $45 / 245(18.4)$ & $0.69(0.49-0.98)$ & 0.040 & $0.63(0.43-0.95)$ & 0.025 \\
\hline \multicolumn{6}{|c|}{ Gram-negative BSI } \\
\hline No statin & $138 / 646(21.4)$ & 1 (reference) & & 1 (reference) & \\
\hline Statin & $14 / 138(10.1)$ & $0.42(0.23-0.75)$ & 0.003 & $0.38(0.20-0.72)$ & 0.003 \\
\hline \multicolumn{6}{|c|}{ Gram-positive BSI } \\
\hline No statin & $128 / 474(27.0)$ & 1 (reference) & & 1 (reference) & \\
\hline Statin & 28/98 (28.6) & $1.08(0.67-1.75)$ & 0.75 & $1.22(0.69-2.17)$ & 0.49 \\
\hline
\end{tabular}

*Adjusted for age ( $<65$ years, 65-79 years, $\geq 80$ years); sex; Charlson comorbidity index; nursing home resident; functional status (independent, partly independent, dependent, unknown); immunosuppressive therapy; alcohol abuse; smoking (no smoking, former smoker, present smoker); focus of infection (urinary tract, lungs, biliary tract, gastrointestinal tract, other, unknown); use of antibiotics before admission; and place of acquisition (community, healthcare, hospital)

negative BSI (adjusted OR 0.38, $95 \%$ CI $0.20-0.72, p=$ 0.003 ). The relations between prior statin use and 90 -day mortality in Gram-negative and Gram-positive BSI were significantly different; the adjusted OR for the interaction term was 2.95 (95\% CI $1.26-6.89, p=0.012)$.

In an analysis including adjustment for appropriate initial antibiotic therapy, the effect estimates did not change (adjusted OR $0.38,95 \%$ CI $0.20-0.73, p=0.004$ and OR $1.21,95 \%$ CI $0.68-2.14, p=0.52$ for Gram-negative and Gram-positive $\mathrm{BSI}$, respectively).

Adjusted ORs for the relation between statin use and 90day mortality were similar when disease categories (e.g., diabetes, cardiovascular disease) were used instead of the Charlson comorbidity index for the total cohort (OR 0.62, $95 \%$ CI 0.41-0.94, $p=0.026$ ), Gram-negative BSI (OR $0.37,95 \%$ CI $0.18-0.74, p=0.005$ ), and Gram-positive BSI (OR 1.13, $95 \%$ CI 0.62-2.07).

After excluding bacterial subgroups with zero statin users $(n=33)$, the association between statin use and 90-day mortality in Gram-negative BSI did not change, either unadjusted (OR $0.44,95 \%$ CI $0.24-0.78, p=0.006$ ) or after adjustment for confounders (OR 0.41, $95 \%$ CI $0.21-0.78, p=0.007$ ).

For some variables included in the main analysis (focus of infection, use of antibiotics before admission, and place of acquisition), the association with prior statin use is unclear, and it is uncertain whether these variables fulfil the criteria for being a confounder. Additionally, we repeated the analysis after excluding these variables from the model, but the relations between prior statin use and 90-day mortality in Gram-negative (OR 0.37, $95 \%$ CI $0.20-0.70, p=0.002$ ) and Grampositive BSI (OR 1.00, $95 \%$ CI 0.58-1.75) remained unchanged.

\section{Discussion}

In this cohort study of patients with BSI, prior statin use was associated with reduced 90-day mortality in Gram-negative, but not in Gram-positive, BSI. To our best knowledge, no previous research has reported this finding. The effect measures were not changed by adjustment for variables that were considered confounding factors.

In the total cohort of BSI, the unadjusted OR for mortality among statin users compared with non-users did not differ much from what has been found by other investigators $[7,9$, 11]. In one study, adjustment for possible confounding factors attenuated the effect measure to a value above 1 [11]. A population-based prospective cohort study on statin use and community-acquired pneumonia [26] raised concerns that previous studies indicating benefits of statins in patients with sepsis had been measuring and reporting a healthy user effect. In that study, statin users were less likely to die or to be admitted to an ICU. After adjusting for confounding factors that reflect patient frailty or healthy user behavior, no reduction in either mortality or the need for admission to an ICU in statin users was found.

In the present study, a significantly lower proportion of statin users were functionally dependent patients or nursing home residents compared with non-users. The proportion of former smokers was significantly higher among statin users. However, these associations of statin use were essentially similar in Gram-negative and Grampositive BSI. Therefore, it seems unlikely that the observed difference in the possible preventive effect of statins between Gram-negative BSI and Gram-positive BSI in our study could be explained by a healthy user effect. 
Most previous investigators have dealt with infection, sepsis, or BSI as if these categories represent homogenous groups with regard to pathogenesis or assumed preventive effect of statins. A few articles reported some data on the relations between statin use and death in Gram-positive and Gram-negative BSI separately. Liappis et al. [4] reported trends of reduced mortality rates in statin users with Gram-negative infection ( $1 / 19$ vs. $48 / 223, p=0.13)$ or Staphylococcus aureus infection (0/15 vs. $22 / 130, p=$ 0.13 ). Yang et al. [10] found a trend of lower mortality in statin users with Gram-negative bacteremia (10.3\% vs. $16.4 \%, p=0.25$ ), but not in Gram-positive bacteremia (33.3\% vs. $27.8 \%, p=0.50)$. Thomsen et al. [7] did not find such a trend in the enterobacterial group of Gramnegative bacteria (adjusted 30-day mortality rate ratio $1.07,95 \%$ CI $0.61-1.86, p=0.82$ ), nor did Leung et al. find a negative association between statin use and death in Gram-negative BSI (adjusted hazard ratio 1.10, 95 \% CI 0.87-1.39) [11]. However, the latter had adjusted for variables expressing the severity of the current infection, i.e., factors that should be considered as mediators rather than confounders, and such an adjustment may attenuate the true associations [22]. Recently, López-Cortés et al. found a negative association between statin use and death within 14 days from Staphylococcus aureus BSI (adjusted OR $0.08,95 \%$ CI $0.01-0.66, p=0.02$ ) [8].

Statins are renowned for their anti-inflammatory and pleiotropic lipid-lowering independent effects. They exert their anti-inflammatory effects through their implication on a variety of molecular pathways of the innate and adaptive immune system, such as their impact on the circulating levels of inflammatory cytokines, as well as anti-coagulant and anti-proliferative effects [27, 28]. With regards to sepsis, many in vitro and animal studies have demonstrated that statins attenuate endotoxininduced inflammatory responses [29]. Similarly, statins have been found to diminish inflammatory responses induced by Staphylococcus aureus lipoteichoic acid [30]. However, there are few studies that have explored the mechanisms for differential effects of statins in Gram-positive and Gram-negative BSI, as observed in the present study. Gram-positive and Gram-negative bacteria have different cell wall components and may stimulate different toll-like receptors (TLRs) on cells of the innate immune system, initiating the transcription of different inflammatory mediator genes. Interestingly, there are several studies showing that statins decrease lipopolysaccharide (LPS) signaling through the downregulation of TLR4 expression on monocytes [31]. Although some studies suggest that statins may also suppress TLR2 signaling in Gram-positive infection, statins may not inhibit the lipoprotein-induced pathway via TLR2 and the LPS-induced pathway via TLR4 to the same extent [32]. Indeed, there are some studies showing that statins inhibit TLR4-mediated activation of interferon regulatory factor 3 (IRF3) and interferon-beta production in macrophages stimulated by LPS, while no such effects were observed for TLR2 stimulation [33]. The clinical relevance of these findings is, however, unknown and require further examination. Nevertheless, they illustrate that there may be molecular mechanisms supporting the findings of different effects of statins in Gram-positive and Gram-negative BSI.

Our findings indicate that the possible preventive effect of statins in BSI may be a subgroup effect seen in Gram-negative, but not in Gram-positive, infection. Whether a negative association between statin use and mortality in Gram-negative BSI really exists as a biological interaction should be further investigated, preferably by randomized controlled studies (RCTs). As of yet, few RCTs have been performed [34, 35], and though several are presently in progress [36], they are designed to study the effect of statin treatment in ongoing infection, not the prophylactic effect of statin use prior to infections. One RCT has shown improved survival in atorvastatin-treated ICU patients with severe sepsis if they had been prior statin users, but no effect was found in patients who received de novo statin therapy [35]. RCTs, so far, have not assessed whether different etiologic agents influence the relation between prior statin use and the outcome of infections.

\section{Strengths and weaknesses of the study}

The strength of our study is that our bacteremia database contains confirmed diagnoses and variables collected from the patients' hospital data, which include medical records. Thus, we have more reliable data than diagnostic information from only discharge databases. Our cohort has a sufficient number of patients in the different groups, which makes it possible to assess the relation between statin use and 90-day mortality, an important endpoint in prior studies.

The study has the weakness of being an observational study, burdened with the risk of confounding. Socioeconomic factors have not been adjusted for, but severe confounding by socioeconomic differences seems unlikely because statin prescriptions are reimbursed, and access to hospital treatment is the same for all citizens in Norway. In addition, we have not adjusted for vaccinations, e.g., pneumococcus vaccine or influenza vaccine, which some previous authors have regarded as "healthy user" markers. Nonetheless, we are not aware of confounders that would be likely to cause a strong association of statin use with reduced mortality in Gram-negative, but not in Gram-positive, BSI. 


\section{Conclusion}

In the present study, the relation between statin use and 90-day total mortality was different in Gram-positive and Gramnegative bloodstream infection (BSI). In Gram-negative BSI, statin use was associated with lower 90-day mortality, which was not the case in Gram-positive BSI.

Acknowledgments This work is supported by the Unit for Applied Clinical Research, Norwegian University of Science and Technology (NTNU); the Liaison Committee between the Central Norway Regional Health Authority (RHA) and the Norwegian University of Science and Technology (NTNU); the Norwegian Surveillance Programme for Antimicrobial Resistance; and Nord-Trøndelag Hospital Trust's Fund for Research and Improvement.

We would like to thank our research nurses for their diligent and accurate work in the data collection process.

Conflict of interest The authors declare that they have no competing interests.

Open Access This article is distributed under the terms of the Creative Commons Attribution License which permits any use, distribution, and reproduction in any medium, provided the original author(s) and the source are credited.

\section{References}

1. Goto M, Al-Hasan MN (2013) Overall burden of bloodstream infection and nosocomial bloodstream infection in North America and Europe. Clin Microbiol Infect 19(6):501-509

2. Martin GS, Mannino DM, Eaton S, Moss M (2003) The epidemiology of sepsis in the United States from 1979 through 2000. N Engl J Med 348(16): 1546-1554

3. Angus DC, Linde-Zwirble WT, Lidicker J, Clermont G, Carcillo J, Pinsky MR (2001) Epidemiology of severe sepsis in the United States: analysis of incidence, outcome, and associated costs of care. Crit Care Med 29(7):1303-1310

4. Liappis AP, Kan VL, Rochester CG, Simon GL (2001) The effect of statins on mortality in patients with bacteremia. Clin Infect Dis 33(8): 1352-1357

5. Kruger P, Fitzsimmons K, Cook D, Jones M, Nimmo G (2006) Statin therapy is associated with fewer deaths in patients with bacteraemia. Intensive Care Med 32(1):75-79

6. Hsu J, Andes DR, Knasinski V, Pirsch J, Safdar N (2009) Statins are associated with improved outcomes of bloodstream infection in solid-organ transplant recipients. Eur J Clin Microbiol Infect Dis 28(11):1343-1351

7. Thomsen RW, Hundborg HH, Johnsen SP, Pedersen L, Sørensen HT, Schønheyder HC, Lervang HH (2006) Statin use and mortality within 180 days after bacteremia: a population-based cohort study. Crit Care Med 34(4):1080-1086

8. López-Cortés LE, Gálvez-Acebal J, Del Toro MD, Velasco C, de Cueto M, Caballero FJ, Muniain MA, Pascual A, Rodríguez-Baño J (2013) Effect of statin therapy in the outcome of bloodstream infections due to Staphylococcus aureus: a prospective cohort study. PLoS One 8(12):e82958

9. Viasus D, Gudiol C, Fernández-Sabé N, Cabello I, Garcia-Vidal C, Cisnal M, Duarte R, Antonio M, Carratalà J (2011) Effect of statins on outcomes in immunosuppressed patients with bloodstream infection. Eur J Clin Microbiol Infect Dis 30(1):77-82
10. Yang KC, Chien JY, Tseng WK, Hsueh PR, Yu CJ, Wu CC (2007) Statins do not improve short-term survival in an oriental population with sepsis. Am J Emerg Med 25(5):494-501

11. Leung S, Pokharel R, Gong MN (2012) Statins and outcomes in patients with bloodstream infection: a propensity-matched analysis. Crit Care Med 40(4):1064-1071

12. Opal SM, Cohen J (1999) Clinical gram-positive sepsis: does it fundamentally differ from gram-negative bacterial sepsis? Crit Care Med 27(8):1608-1616

13. Leaver SK, Finney SJ, Burke-Gaffney A, Evans TW (2007) Sepsis since the discovery of Toll-like receptors: disease concepts and therapeutic opportunities. Crit Care Med 35(5):1404-1410

14. Nolte FS, Williams JM, Jerris RC, Morello JA, Leitch CD, Matushek S, Schwabe LD, Dorigan F, Kocka FE (1993) Multicenter clinical evaluation of a continuous monitoring blood culture system using fluorescent-sensor technology (BACTEC 9240). J Clin Microbiol 31(3):552-557

15. Yende S, Milbrandt EB, Kellum JA, Kong L, Delude RL, Weissfeld LA, Angus DC (2011) Understanding the potential role of statins in pneumonia and sepsis. Crit Care Med 39(8):1871-1878

16. Cohen J, Guyatt G, Bernard GR, Calandra T, Cook D, Elbourne D, Marshall J, Nunn A, Opal S; UK Medical Research Council International Working Party (2001) New strategies for clinical trials in patients with sepsis and septic shock. Crit Care Med 29(4):880 886

17. Charlson ME, Pompei P, Ales KL, MacKenzie CR (1987) A new method of classifying prognostic comorbidity in longitudinal studies: development and validation. J Chronic Dis 40(5):373-383

18. Friedman ND, Kaye KS, Stout JE, McGarry SA, Trivette SL, Briggs JP, Lamm W, Clark C, MacFarquhar J, Walton AL, Reller LB, Sexton DJ (2002) Health care-associated bloodstream infections in adults: a reason to change the accepted definition of community-acquired infections. Ann Intern Med 137(10):791-797

19. Shorr AF, Tabak YP, Killian AD, Gupta V, Liu LZ, Kollef MH (2006) Healthcare-associated bloodstream infection: a distinct entity? Insights from a large U.S. database. Crit Care Med 34(10):25882595

20. Levy MM, Fink MP, Marshall JC, Abraham E, Angus D, Cook D, Cohen J, Opal SM, Vincent JL, Ramsay G; International Sepsis Definitions Conference (2003) 2001 SCCM/ESICM/ACCP/ATS/ SIS International Sepsis Definitions Conference. Intensive Care Med 29(4):530-538

21. Vincent JL, de Mendonça A, Cantraine F, Moreno R, Takala J, Suter PM, Sprung CL, Colardyn F, Blecher S (1998) Use of the SOFA score to assess the incidence of organ dysfunction/failure in intensive care units: results of a multicenter, prospective study. Working group on "sepsis-related problems" of the European Society of Intensive Care Medicine. Crit Care Med 26(11):1793-1800

22. Rothman KJ (2012) Epidemiology: an introduction. Oxford University Press, Oxford

23. Thomsen RW, Riis A, Kornum JB, Christensen S, Johnsen SP, Sørensen HT (2008) Preadmission use of statins and outcomes after hospitalization with pneumonia: population-based cohort study of 29,900 patients. Arch Intern Med 168(19):2081-2087

24. Niederman MS, Mandell LA, Anzueto A, Bass JB, Broughton WA, Campbell GD, Dean N, File T, Fine MJ, Gross PA, Martinez F, Marrie TJ, Plouffe JF, Ramirez J, Sarosi GA, Torres A, Wilson R, Yu VL; American Thoracic Society (2001) Guidelines for the management of adults with communityacquired pneumonia. Diagnosis, assessment of severity, antimicrobial therapy, and prevention. Am J Respir Crit Care Med 163(7):1730-1754

25. Lydersen S, Langaas M, Bakke Ø (2012) The exact unconditional zpooled test for equality of two binomial probabilities: optimal choice of the Berger and Boos confidence coefficient. J Stat Comput Simul 82(9):1311-1316 
26. Majumdar SR, McAlister FA, Eurich DT, Padwal RS, Marrie TJ (2006) Statins and outcomes in patients admitted to hospital with community acquired pneumonia: population based prospective cohort study. BMJ 333(7576):999

27. Terblanche M, Almog Y, Rosenson RS, Smith TS, Hackam DG (2007) Statins and sepsis: multiple modifications at multiple levels. Lancet Infect Dis 7(5):358-368

28. Owens AP 3rd, Passam FH, Antoniak S, Marshall SM, McDaniel AL, Rudel L, Williams JC, Hubbard BK, Dutton JA, Wang J, Tobias PS, Curtiss LK, Daugherty A, Kirchhofer D, Luyendyk JP, Moriarty PM, Nagarajan S, Furie BC, Furie B, Johns DG, Temel RE, Mackman N (2012) Monocyte tissue factor-dependent activation of coagulation in hypercholesterolemic mice and monkeys is inhibited by simvastatin. J Clin Invest 122(2):558-568

29. Matsumoto M, Einhaus D, Gold ES, Aderem A (2004) Simvastatin augments lipopolysaccharide-induced proinflammatory responses in macrophages by differential regulation of the c-Fos and c-Jun transcription factors. J Immunol 172(12):7377-7384

30. Wu BQ, Luo JM, Wang YH, Shi YF, Liu H, Ba JH, Zhang TT (2014) Inhibitory effects of simvastatin on Staphylococcus aureus lipoteichoic acid-induced inflammation in human alveolar macrophages. Clin Experiment Med 14(2):151-160

31. Methe H, Kim JO, Kofler S, Nabauer M, Weis M(2005) Statins decrease Toll-like receptor 4 expression and downstream signaling in human CD14+ monocytes. Arterioscler Thromb Vasc Biol 25(7):1439-1445
32. Niessner A, Steiner S, Speidl WS, Pleiner J, Seidinger D, Maurer G, Goronzy JJ, Weyand CM, Kopp CW, Huber K, Wolzt M, Wojta J (2006) Simvastatin suppresses endotoxin-induced upregulation of toll-like receptors 4 and 2 in vivo. Atherosclerosis 189(2):408-413

33. Abe M, Matsuda M, Kobayashi H, Miyata Y, Nakayama Y, Komuro R, Fukuhara A, Shimomura I (2008) Effects of statins on adipose tissue inflammation: their inhibitory effect on MyD88-independent IRF3/IFN-beta pathway in macrophages. Arterioscler Thromb Vasc Biol 28(5):871-877

34. Papazian L, Roch A, Charles PE, Penot-Ragon C, Perrin G, Roulier P, Goutorbe P, Lefrant JY, Wiramus S, Jung B, Perbet S, Hernu R, Nau A, Baldesi O, Allardet-Servent J, Baumstarck K, Jouve E, Moussa M, Hraiech S, Guervilly C, Forel JM; STATIN-VAP Study Group (2013) Effect of statin therapy on mortality in patients with ventilator-associated pneumonia: a randomized clinical trial. JAMA 310(16): 1692-1700

35. Kruger P, Bailey M, Bellomo R, Cooper DJ, Harward M, Higgins A, Howe B, Jones D, Joyce C, Kostner K, McNeil J, Nichol A, Roberts MS, Syres G, Venkatesh B; ANZ-STATInS Investigators-ANZICS Clinical Trials Group (2013) A multicenter randomized trial of atorvastatin therapy in intensive care patients with severe sepsis. Am J Respir Crit Care Med 187(7):743-750

36. Kouroumichakis I, Papanas N, Proikaki S, Zarogoulidis P, Maltezos E (2011) Statins in prevention and treatment of severe sepsis and septic shock. Eur J Intern Med 22(2):125-133 